\title{
THE THERAPEUTIC APPLICATION OF RADIOACTIVE PHOSPHORUS WITH SPECIAL REFERENCE TO THE TREATMENT OF PRIMARY POLYCYTHEMIA AND CHRONIC MYELOID LEUKEMIA ${ }^{1}$
}

\author{
BY HYMER L. FRIEDELL AND JOHN P. STORAASLI
}

\author{
(From the Department of Radiology, University Hospitals, and Western Reserve University \\ School of Medicine, Cleveland, Ohio)
}

The use of radioactive phosphorus in the treatment of disease stems from the initial studies made by Lawrence and his colleagues in 1936 (1). Since then there have been a number of reports which establish the efficacy of this form of therapy in chronic leukemia and polycythemia (2-11). These clinical reports have been issued from a number of separate institutions, indicating that independent experiences are now fairly widespread. The report by Reinhard et al. (12) is an exhaustive review of the clinical course of patients treated in this fashion. Similar studies by Doan et al. (13) and Lawrence et al. (14) add extensively to the data now available in the literature. It is our intention here to add to the clinical observations presented in the previous reports, but we wish particularly to emphasize the pertinent information available from the literature and from our own work which is the basis and rationale for such treatment.

The concept of treating disease with internally distributed radioactive materials is not completely new and attempts in this direction have previously been made by introducing into the blood stream some of the naturally occurring elements, such as radium. However, the invention of the cyclotron and more recently the development of high energy nuclear reactors of the Atomic Energy Commission have given considerable impetus to this concept of therapy. This is particularly true because of the wide variety of radioactive elements which can be produced by these devices, some of which have suitable characteristics (desirable half-life, proper radiation characteristics, and satisfactory chemical properties).

The rationale of treating patients with radioactive material arises from the desire to irradiate selectively certain specific tissues and to prolong

1 Some of the work was performed under A.E.C. contract No. W-31-109-eng-78 with Western Reserve University. Also supported in part by a grant from the Elsa U. Pardee Foundation. the irradiation over one or more life cycles of the cells to be irradiated. Ever since it became clear that ionizing radiation could affect malignant tumors and allied conditions in a beneficial manner, selective localization has been continually sought after. The radiation would thus be localized primarily in a specific tissue or organ, sparing the normal remaining tissue from any deleterious effect. Even when external radiation is employed, an effort is made to localize the radiation in a specific site. This is achieved with external X-rays by means of cross-firing techniques and sharply limited portals.

At the present time the outstanding example of selective localization concerns itself with the deposition of iodine in the thyroid gland and the use of radioactive iodine for treatment of diseases of this gland arises from this highly specific localization.

In the case of $\mathrm{P}^{32}$, a similar though much less pronounced selective deposition exists in leukemic tissue, in the erythrocytogenic tissues in primary polycythemia, and in certain rapidly growing tumors. Moreover, $\mathrm{P}^{32}$ is preferentially deposited in bone, since phosphate is a continuous requirement and important constituent of bone. This further adds selective radiation to the bone marrow which, in general, is the important site of the two diseases noted above.

In addition to selective localization in the case of various radioactive elements, the differential sensitivity of cells during various phases of the mitotic cycle must be considered. If it is true that cells are affected by radiation only during certain phases of the mitotic cycle, then prolonged lowgrade radiation such as that which can be achieved by the use of $\mathrm{P}^{32}$ may be highly desirable. The fact that rapidly metabolizing, poorly differentiated tissues are sensitive to radiation may be another important factor.

It is known that phosphorus introduced into the blood stream in the form of a readily diffusible 
and ionizable phosphate will be available to all tissues of the body and those tissues which utilize phosphorus in their metabolic processes will rapidly take up this element. The rate of uptake and the deposition of phosphorus-and here there is no distinction between radioactive phosphorus and ordinary phosphorus-is a function of several things.

1. The metabolic turn-over rate will determine the rate at which a specific cellular structure will reach equilibrium with its milieu. This is dependent upon (a) the metabolic activity of the tissue, and $(b)$ its rate of growth. The two may be closely intertwined and inseparable.

2. The need for phosphorus, or indirectly, the amount of phosphorus ordinarily present in any specific tissue. This will be a gross index of the prospective uptake of $\mathrm{P}^{32}$.

3. The chemical nature of the phosphorus compound, that is, whether it is easily ionizable, bound to organic compounds, or in insoluble form, determines in considerable measure the uptake in any specific tissue. An example of an insoluble form is chromic phosphate which is made up in a suspension and after being introduced intravenously is deposited in the reticulo-endothelial system of the liver, spleen and bone marrow.

4. The permeability of the cell membrane. The characteristics of the membrane, the $\mathrm{pH}$ of the cell environment, and other factors undoubtedly contribute to the transfer of phosphorus into the cell.

If, theoretically, all tissues of the body, normal and neoplastic, had the same type of phosphorus containing constituents and the same turn-over rate, the use of $\mathrm{P}^{32}$ would be entirely without rationale and would correspond to external spray irradiation with $\mathrm{X}$-rays. It is well known and well established, however, that normal cells of various tissue structures have different metabolic and turn-over rates and different phosphorus requirements. When $\mathrm{P}^{32}$ is introduced into the body, differing levels of radioactive phosphorus will thus occur in the different tissues. In addition to this, tissues in which replacement is rapid (thus producing a rapid metabolic uptake of all the elements and compounds which enter into the constituent of the cell) approach equilibrium much more rapidly than cells of lower activity and thus achieve a higher level of radioactive phosphorus and a correspondingly higher level of radiation than the less active cell.

If we assume a constant amount of $\mathrm{P}^{32}$ in the vascular and intracellular fluid, then the tissue cells in any organism will have the same specific activity of $\mathrm{P}^{32}$ (the ratio of active to inactive phosphorus) when the organism finally reaches equilibrium. Before equilibrium is reached, however, those tissues having the more rapid metabolic rate and turn-over will contain more $\mathrm{P}^{32}$ or, more precisely, a higher specific activity of $\mathrm{P}^{32}$ will exist. If no difference in the metabolic and turn-over rate exists, then the rate at which equilibrium is approached is the same for all tissues and specific activity is the same for all tissues at all times.

In the actual therapeutic application of radioactive phosphorus certain information must be available for orientation in this means of therapy.

1. Information about the pertinent characteristics of the radiation from $\mathrm{P}^{32}$ and its radioactivity constants is essential.

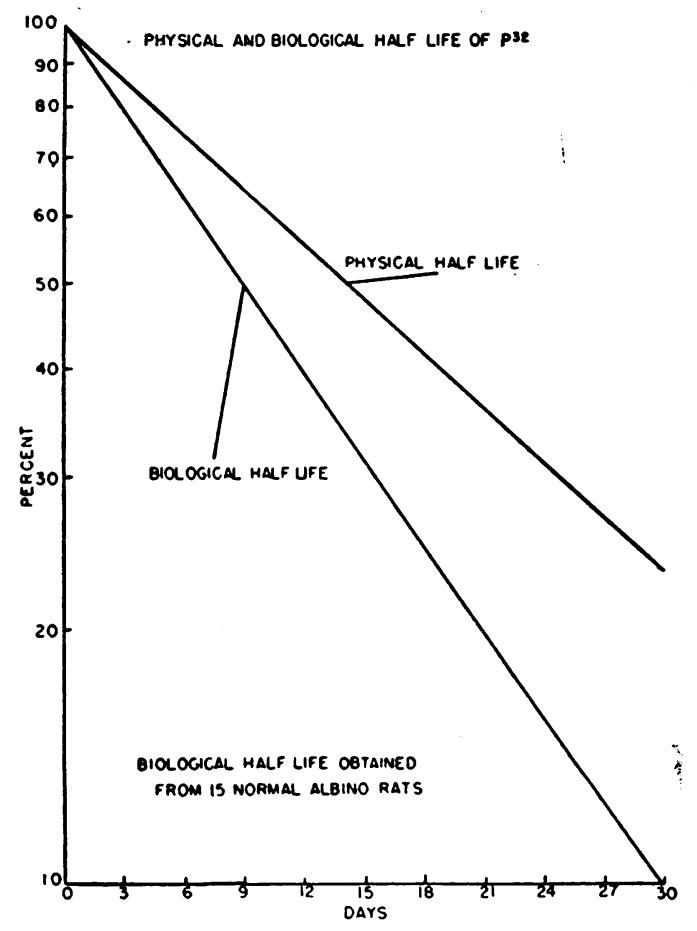

FIG. 1.

The biological half-life is valid only after the third day, at which time $62 \%$ of the injected dose was retained. It is a composite curve of the amount excreted plus the decay of the $\mathrm{P}^{\prime 2}$. 
2. The known phosphorus stores and requirements of the various tissues of the body should be known. The amount and kind of phosphoruscontaining compounds is important and the distribution of nuclear proteins, phosphatides, and inorganic phosphate is very helpful.

3. The turn-over rate or metabolic activity of specific normal tissues as well as neoplastic tissue should be evaluated if possible.

4. The rate at which radioactive phosphorus disappears from the body in the excreta should be ascertained. Reference is occasionally made to the biological half-life which is a composite of the rate of loss from the body together with the rate of loss by natural decay (see Figure 1). Obviously this is important in deciding about dosage determinations.

5. The biological effects of the radiation from $\mathrm{P}^{32}$ must be appreciated. This can be roughly divided into $(a)$ lethal effects, $(b)$ specific effects on sensitive tissues such as depression of the white blood cells in the hematopoietic system, and (c) other effects, such as radiation necessary to produce erythema of the skin, etc.

Characteristics of $P^{32}$. $\mathrm{P}^{32}$ has radiation and disintegration characteristics which are readily adaptable to biological purposes. ${ }^{2}$ The half-life of $\mathrm{P}^{32}$ is 14.3 days. It emits a beta particle whose peak energy is 1.69 MEV and which has an aver- age energy of $0.7 \mathrm{MEV}$. Thus, the peak range in tissue is about $8 \mathrm{~mm}$. and the average range is approximately $2 \mathrm{~mm}$. Therefore, in a large mass of tissue, the radiation is essentially localized in the tissue in which the phosphorus is deposited.

The dosage calculations of radiophosphorus, or a calculation of the energy absorbed per unit mass of tissue, are easily made and are often converted into roentgen equivalents, since a great deal of biological information is available on external radiation which has been measured by means of this unit. Since the roentgen is defined in terms of the ionization occurring in a fixed mass of air, it is possible therefore to convert energy absorbed by tissue from internally distributed radioactive elements into roentgens, sometimes referred to as roentgen equivalent physical (rep), or roentgen equivalent.

It is necessary to know the distribution of the radioactive element in tissue, that is, the number of microcuries ${ }^{3}$ per unit mass of tissue, the energy available on the average from each beta particle emitted by phosphorus, and the number of ergs corresponding to one roentgen. (This is derived from the original definition of the roentgen by introducing the energy required to produce an ion pair.) The calculations for one microcurie per gram for complete decay are as follows:

Calculation of tissue dosage in roentgens due to the complete decay of 1 microcurie of $P^{32}$ in gram of tissue

Half-life $=14.3$ days

Average life $=\frac{14.3 \times 86,400}{\ln _{\bullet} 2}=14.3 \times 86,400 \times 1.443$ seconds

Average energy per disintegration $=$ Peak energy $\times 0.4=1.69 \times 0.4 \mathrm{MEV}$ roentgens

$$
\begin{aligned}
& =\frac{\text { (microcuries)(dis./sec./microcuries)(aver. life in sec.)(aver. energy in MEV)(ergs/MEV) }}{\text { ergs/roentgen }} \\
& =\frac{(1)\left(3.71 \times 10^{4}\right)(14.3 \times 86,400 \times 1.443)(1.69 \times 0.4)\left(1.6 \times 10^{-6}\right)}{83} \\
& =857 \text { (roentgens for complete decay of } 1 \text { microcurie in } 1 \text { gram of tissue) }
\end{aligned}
$$

\footnotetext{
${ }^{2}$ Radioactive phosphorus was first produced in the cyclotron by E. O. Lawrence by the bombardment of red phosphorus placed in the external target chamber or the bombardment of an iron phosphide probe placed in the deuteron beam ( $d, p$ reaction). Since the development of the piles or nuclear reactors now being operated by the Atomic Energy Commission, radiophosphorus is now made primarily from sulfur by the $n, p$ reaction, producing essentially carrier-free $P^{23}$. It is also possible to produce phosphorus in the pile by the $n$, gamma reaction. The n,p reaction with sulfur obviously provides carrier-free material.
}

81 microcurie is $10^{-6}$ curies. A curie is defined as 3.7 $10^{10}$ disintegrations per second.

Radioassay of $\mathrm{P}^{22}$. Shipments of $\mathrm{P}^{20}$ from Oak Ridge are in the form of aqueous solutions of $\mathrm{H}_{3} \mathrm{PO}_{4}$ at $\mathrm{pH}$ 3-5. These samples, properly diluted, are evaporated on a silver disc so as to approximate closely the size and activity of the deposit of the $\mathrm{RaD}+\mathrm{E}$ standards distributed by the Bureau of Standards. These samples are then counted along with the $\mathrm{RaD}+\mathrm{E}$ standard and absorption curves run for both. A value of the count at zero absorber is obtained by extrapolating the above curves to zero, allowing for the thickness of the G-M 
AVERAGE GENERAL DISTRIBUTION OF P32 FOR 14 OAYS IN 16 NORMAL ALBINO RATS

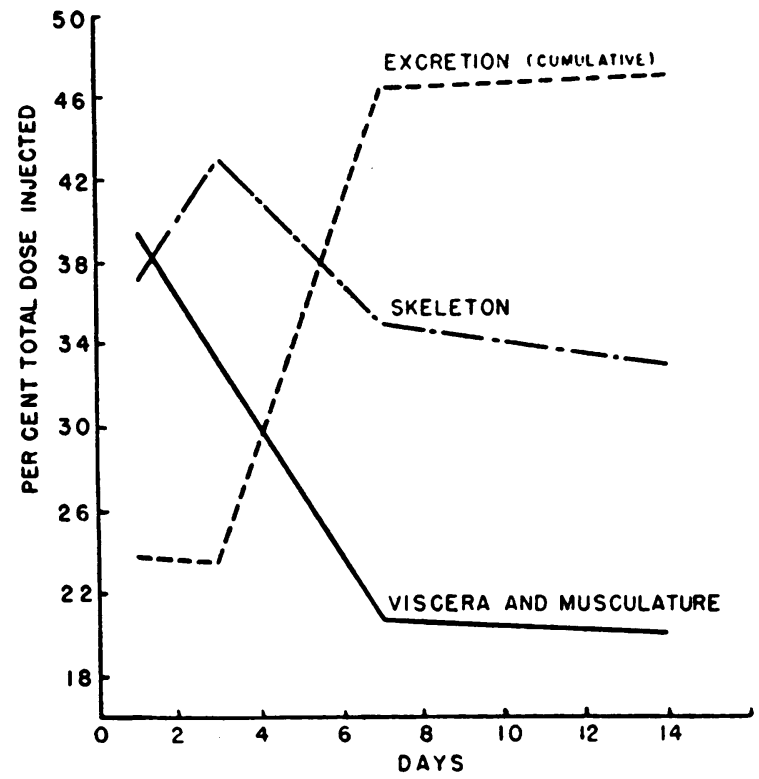

FIG. 2

The curve shows the distribution of retained $\mathrm{P}^{22}$ in skeleton and viscera and the amount excreted for intervals throughout 14 days. The amount retained in the skeleton progressively increases beyond the 14 day period.

Phosphorus content of normal tissue. The normal phosphorus stores of the various tissues of the body are an important consideration in the feasibility of treatment with ionizable $\mathrm{P}^{32}$. Since the stores of phosphorus in the tissues generally reflect the need for phosphorus, the amount of $\mathrm{P}^{32}$ taken up in tissue will be directly related to this need. Bone, therefore, contains more phosphorus than any other tissue. Figure 2 indicates the character of the distribution of intraperitoneally administered $\mathrm{P}^{32}$ in the skeleton and the soft tissues over the first two weeks.

Cohn and Greenberg (15) found that retention of $\mathrm{P}^{32}$ per unit fresh weight in various tissues decreased in the following order: bone, liver, in-

tube window and additional air absorber. By comparing the zero absorber counts of the $\mathrm{P}^{s 2}$ and the $\mathrm{RaD}+\mathrm{E}$ standard, an absolute millicurie value is obtained for the $\mathbf{P}^{22}$. This value must be corrected, however, for the difference in backscattering from silver of the beta particles of $\mathrm{P}^{22}$ and the $\mathrm{RaD}+\mathrm{E}$ standard. This correction, when applied, reduces the above absolute millicurie value by $7 \%$. Results obtained by this method generally check with the assay of the Oak Ridge National Laboratories values to within $5 \%$. testine, heart, kidney, lung, muscle, skin and brain. After 98 days, $92 \%$ of the retained phosphorus was present in the skeleton. Studies made on rats in which amounts of $\mathrm{P}^{32}$ were considerably greater than tracer doses, gave the distribution as seen in Table I.

The turn-over rate, or metabolic activity of various normal and neoplastic tissue. Some concept of the metabolic activity with regard to phosphorus in the various normal tissues as well as abnormal cellular growths is very important. The greater differential absorption rate in growing tissue as compared with adult tissues has been shown in tissue culture by Bulliard et al. (16). Comparison of the uptake of $\mathrm{P}^{32}$ of neoplastic and normal tissues has been made by Kenney et al. (17) and by Lawrence and his associates (18-21). It has been demonstrated quite conclusively that more $\mathrm{P}^{32}$ is present in the rapidly growing tissue than in

TABLE I

Per cent of intraperitoneally injected $P^{28}$ present in various tissues of albino rats

\begin{tabular}{l|c|c|c}
\hline \multicolumn{1}{c|}{ Organ } & 1 day & 7 days & 14 days \\
\hline 1. Skeleton & 45.0 & 41.5 & 34.2 \\
2. Muscle & 19.4 & 10.8 & 16.2 \\
3. Digestive Tract & 14.4 & 2.5 & 4.2 \\
4. Liver & 9.2 & 1.3 & 1.8 \\
5. Skin & 5.4 & 1.4 & 2.0 \\
6. Brain & 0.13 & 0.20 & 0.20 \\
\hline
\end{tabular}

normal tissue, and particularly high in neoplastic tissue. Forssberg and Jacobsson (22) found in their studies of animals with intravenously labeled phosphate that, in the case of transplanted BrownPearce tumors, the metastatic tumor took up as much $\mathrm{P}^{32}$ as other active organs (spleen, liver, kidney) and about five times as much as less active tissue (diaphragm, omentum, lymph nodes, pleura). Forssberg (23) investigated the uptake of $\mathrm{P}^{32}$ by bone metastases and found that these would take up much larger amounts of $\mathrm{P}^{32}$ per gram of wet weight than a corresponding weight of normal bone. The work of Marshak (24) in comparing the uptake of $\mathrm{P}^{32}$ in the nuclei and cytoplasm of normal and malignant cells indicates that the malignant cells not only accumulate more $\mathrm{P}^{\mathbf{3 2}}$ than the normal cells, but that the relative proportion of administered phosphorus in the nucleus as compared to the cytoplasm is much greater in the malignant cell than in the normal cell. This is 
true not only for malignant cells but for rapidly multiplying normal cells.

Studies of the distribution of $\mathrm{P}^{32}$ taken up in the nucleo-protein, phosphatide, and acid-soluble fractions in normal tissues, leukemic tissues, and tumor tissues, indicate that the highest uptake was present in the nucleo-protein of leukemic and tumor cells. The differences between the various phosphatide and acid-soluble fractions were not remarkable. It is apparent that the nucleo-proteins of leukemic and tumor cells were synthesized more rapidly than those of normal cells of the mouse, and therefore incorporated more $\mathrm{P}^{32}$. Since no important differences exist between the normal phosphorus content of the nucleo-protein fractions of the various tissues, the specific activity of the nucleo-proteins of the leukemic and tumor cells are therefore higher than that of normal cells.

Rate of loss from the body. Information on the rate at which material is lost from the body is vital. In order to determine the effectiveness of therapy it will be necessary to determine the amount of material actually distributed in the tissues. There are considerable discrepancies between various individuals in the amount retained. It is possible, however, to collect the excreta of patients during the treatment period and ascertain precisely the amount distributed in the body. The information which is gained in this way is difficult to apply in a practical manner. In general, it has been found that patients excrete $5 \%$ to $25 \%$ of the administered $\mathrm{P}^{32}$ in the first four to six days when given intravenously, and $15 \%$ to $50 \%$ in the first four to six days when given by mouth (25). It is generally recognized that the retained dose of the material given by mouth is $75 \%$ of that given intravenously. Figure 3 shows corollary data which have been obtained in rats, indicating the rate of excretion which may be expected after intraperitoneal administration. At the end of two weeks $46 \%$ is excreted, and of the remaining, $20 \%$ is in the viscera and musculature, and $33 \%$ in the bone. The ratio of bone deposition to soft tissue deposition continues to increase with time. The figure for bone has added significance when one recognizes that bone comprises only $10 \%$ of the body weight.

It has been shown that the rate of retention in leukemic patients is higher than in normal for the first few days but it is not improbable that after the first week or ten days the excretion rates in normal and leukemia patients are comparable. In calculating dosage, the biological halflife, which is a combination of the excretion rate and the physical decay rate, is actually more helpful than the physical decay rate alone (see Figure 1).

Biological effectiveness. The biological effectiveness of radiation from $\mathrm{P}^{\mathbf{3 2}}$ must be evaluated for each separate system in the body. However, a broad general idea may be obtained from the rate

EQUILIBRIUM AND EXCRETION CURVES FOR P32 FOR I5 NORMAL ALBINO RATS

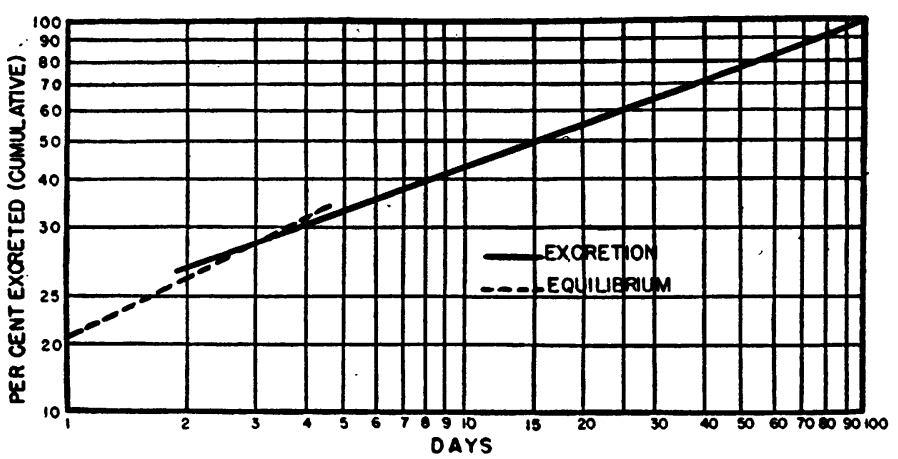

FIG. 3

The rate of excretion changes after the third day. Prior to this, the excretion is definitely more rapid and the curve has been arbitrarily called the equilibrium curve. 
15 DAY SURVIVAL CURVE IN WISTAR STRAIN ALBINO RAT GIVEN P32 INTRAPERITONEALLY

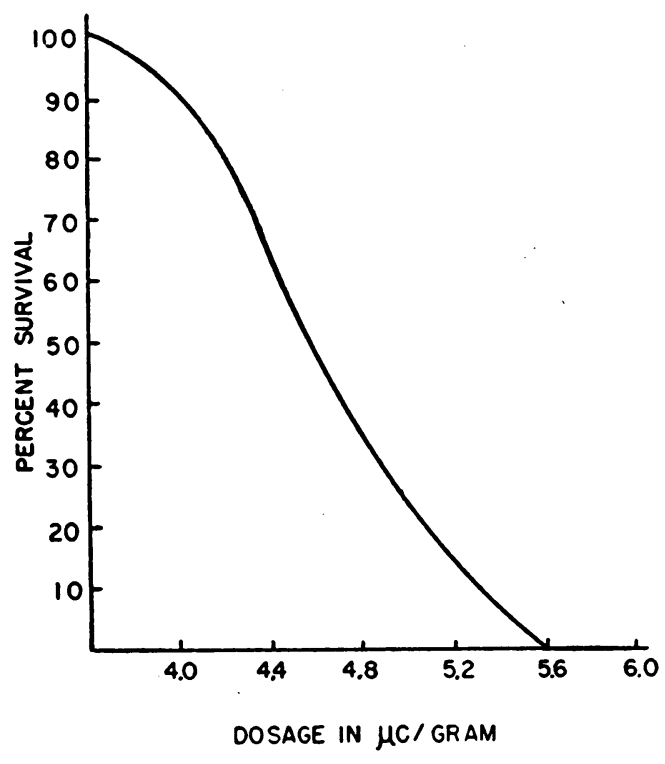

FIG. 4

The $\mathrm{LD}_{s 0}$ for $\mathrm{P}^{32}$ given intraperitoneally is approximately 4.5 microcuries per gram in the albino rat (for a 15 day period).

of survival and in Figure 4 a survival curve is shown for rats having received $\mathrm{P}^{32}$ intraperitoneally. The $\mathrm{LD}_{50}$ for a 15 day period is about 4.5 microcuries of administered $\mathrm{P}^{82}$ per gram of body weight. These animals die of severe leukopenia, thrombocytopenia and anemia. There are numerous foci of infection and severe hemorrhagic manifestations throughout the body. Observations have been made with regard to the total maximum depression in the white blood count. Increasing doses show an increase in the total maximum depression. We have found in rats that 0.7 microcuries per gram of body weight produces a maximum depression of about $50 \%$ occurring in ten days.

Studies have been made of erythemas produced on the skin by Osgood et al. (26). The dose to produce a threshold erythema was found to be 34 microcurie hours per square centimeter.

\section{CLINICAL RESULTS WITH $\mathbf{P}^{32}$}

In the past two years, over 50 patients have been treated with radioactive phosphorus at the University Hospitals of Cleveland. In this number are included the chronic leukemias (myeloid and lymphatic), primary polycythemias, several acute leukemias in children, a selected group of breast carcinomas which have metastasized widely to bone, and a small number of miscellaneous conditions in which it was thought desirable to observe the effect of $\mathrm{P}^{32}$. There were no cases of Hodgkin's disease or lymphosarcoma since the experience with these diseases is, at best, uncertain when treated by $\mathrm{P}^{32}$ and because their response to $\mathrm{X}$-ray, at least in the earlier stages of the disease, is generally good. In addition, the treatment of ordinary uncomplicated lymphoid leukemias with $\mathrm{P}^{32}$ has been avoided since the bone marrow, although infiltrated with lymphoid elements, is not hyperplastic and the normal elements of the marrow receive unnecessarily heavy radiation. The six cases of lymphatic leukemia included in this study were those which had failed to respond to previous $\mathrm{X}$-ray or were cases in which the disease was so widespread that the immediate outlook was very poor. This accounts for the fact that all the patients with lymphoid leukemia were dead within seven months following the beginning of $\mathrm{P}^{32}$ therapy. All the patients reported here had sternal marrow biopsies showing marked displacement of the normal marrow elements by mature and immature lymphocytes.

As has been demonstrated by others, primary polycythemias show excellent response to $\mathrm{P}^{32}$. The response in this group is followed closely by that occurring in chronic myeloid leukemias after treatment with phosphorus.

The cases of acute leukemia, all occurring in children, in general responded very poorly. One individual, however, received definite beneficial effect with a remission which lasted for almost a year-the patient dying at the end of this period. There were widespread destructive lesions in bone which showed considerable improvement following therapy.

It is our intention here to report in detail the primary polycythemias and chronic leukemias since these have received greatest attention in the literature previously and for which the broadest background exists.

Polycythemia rubra vera. Ten cases of primary polycythemia have been treated with radioactive phosphorus. Table II gives a brief summary of the clinical and hematological data for each pa- 


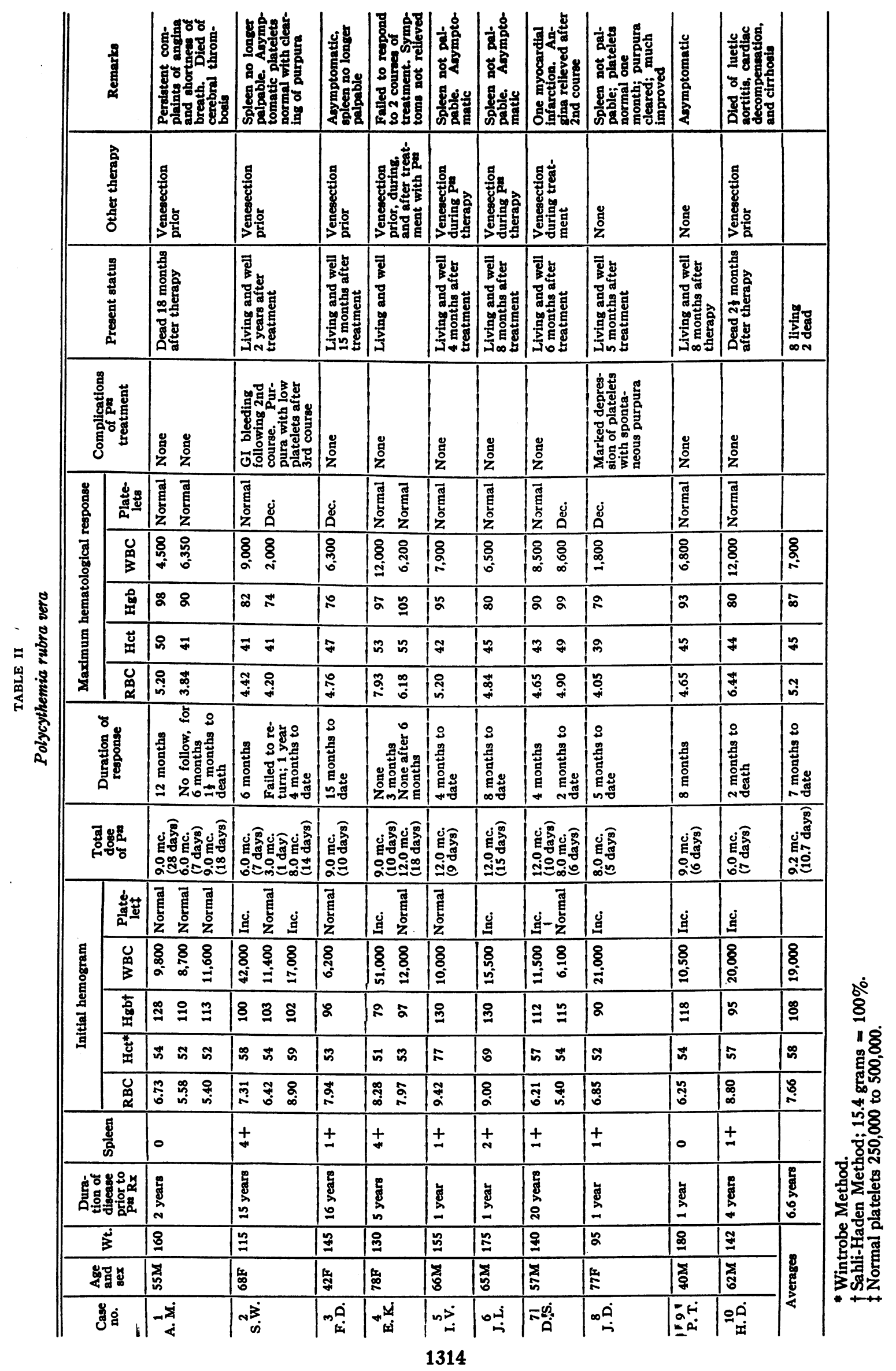


POLYCYTHEMIA RUBRA VERA

(I)

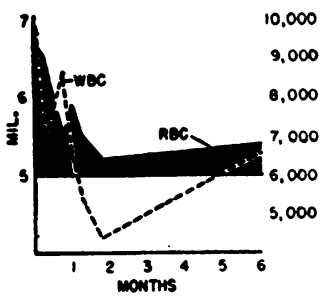

(4)

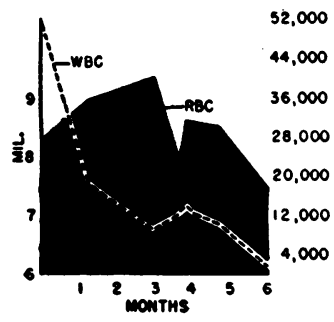

(7)

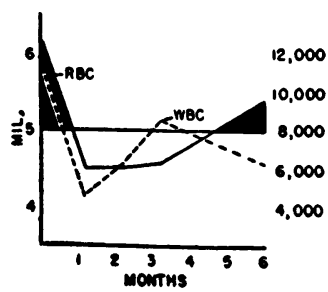

(2)

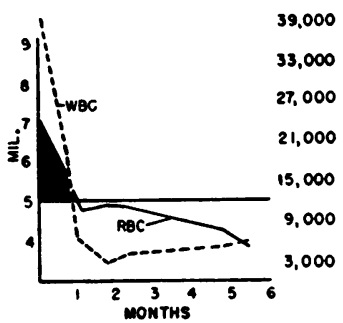

(5)

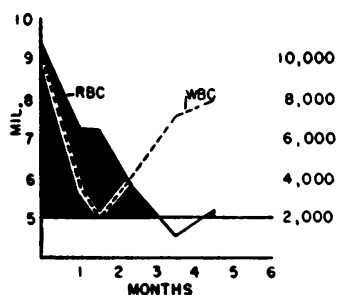

(8)

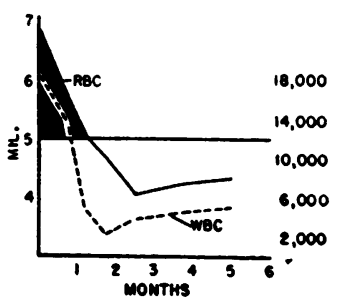

(3)

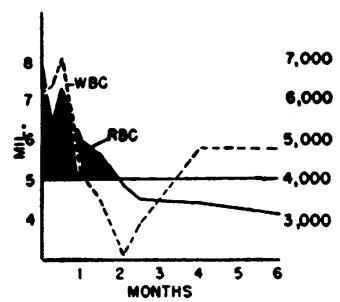

(6)

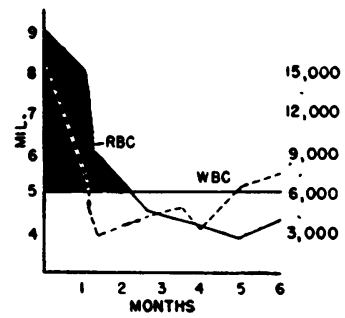

(9)

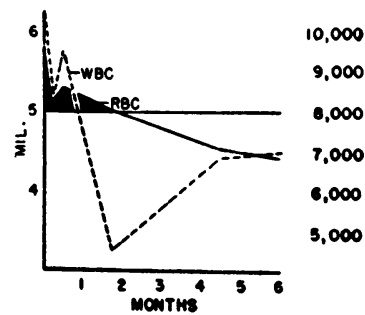

FIG. 5

These curves are the initial hematological responses to $\mathrm{P}^{32}$ of the first nine cases. Case 10 was omitted because death occurred before complete hematological response was obtained.

tient, and Figures 5 and 6 give graphically the initial hematological response of the first nine patients and a composite average response of the group.

In Table II it may be observed that all cases had initial red blood cell counts ranging from 6.21 to 9.4 million per cubic millimeter of blood; the hematocrits range from $51 \%$ to $77 \%$ (Wintrobe method) and the platelets were either normal or increased in number. In the majority of the cases the white cell counts were above normal. In all but two cases a palpable spleen was present. The sternal marrow biopsies showed normal or hyperplastic cellularity.

The response to $\mathrm{P}^{32}$ was reasonably prompt. The peripheral blood counts showed definite evidence of response at about one month and the response was maximum in a period of approximately three to four months. Coincidentally, an immediate depression of the white cell count occurred. The average initial white blood cell count was
19,000 per cubic millimeter and leveled off just above 5,000 white blood cells per cubic millimeter after treatment (see Figure 6). In two of our cases, marked depression of the platelet count was demonstrated. This was accompanied by purpura and spontaneous dependent ecchymosis (Cases 2 and 8). In Case 2, this occurred after the third course of phosphorus. After the initial episode, neither patient showed further evidence of hemorrhage and the thrombocyte counts returned to essentially normal levels. Two cases (Nos. 1 and 4 ) failed to respond adequately to $P^{32}$. The reason for failure in these two cases is obscure. The diagnosis of primary polycythemia in Case 1 may have been in error. Since chronic lung disease was present, it is possible that this may be a secondary polycythemia.

To date, the duration of remissions in the eight cases responding favorably ranges from four to $\mathbf{1 5}$ months with an average remission period of approximately seven months. However, we have 


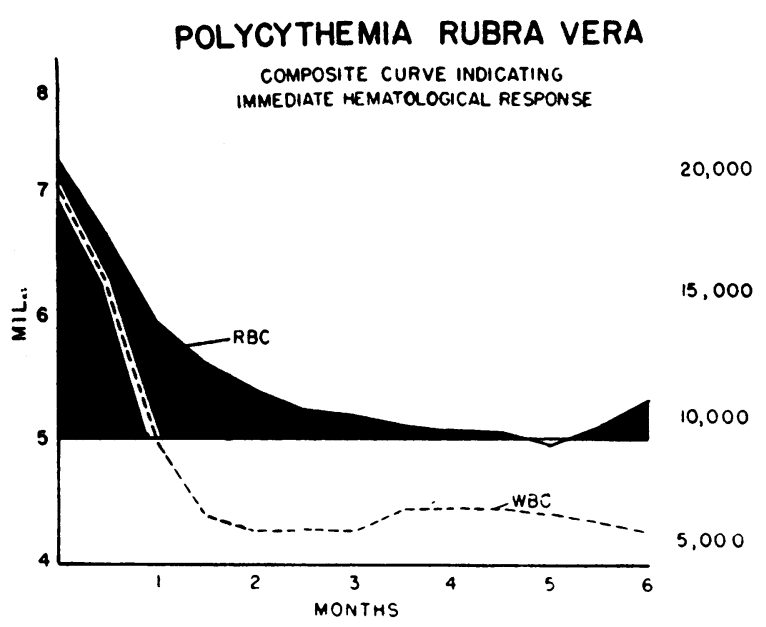

Fig. 6

Case 10 was omitted from the composite curve. The patient died two and one-half months after therapy was instituted. The average maximum response in the red blood count is obtained in five months, as shown by this curve.

not yet followed these cases long enough to have a definite opinion on the length of the remission period. The indications are that these intervals will be comparable to those observed by others.

The criteria for selecting cases have concerned themselves with evidence of the typical triad of polycythemia, that is, megakaryocytic, erythroid and myeloid hyperplasia. This was present in all the cases. Cases showing less than 6 million red blood cells per cubic millimeter were not treated.

Dosage. The dosage levels for polycythemia have not been rigid or fixed. At present, a dose of 100 to 150 microcuries per kilogram administered over a period of ten days to two weeks appears to produce a satisfactory remission in the majority of cases. Occasionally the administration has been continued over a longer period of time. In general, it has been our tendency to treat polycythemias cautiously since it is not possible to gauge the dosage from the hematological response until approximately three months have elapsed. For this reason it is found necessary to repeat the course in some of the cases after this period of time.

Chronic myeloid leukemia. To date, 15 cases of chronic myeloid leukemia have been treated with $\mathrm{P}^{32}$. Table III gives the clinical and hematological course for each patient. Of the 15 cases, two failed to respond to treatment with $\mathrm{P}^{32}$ in what was considered adequate doses. In Case 10, treatment was stopped because of marked depression of the platelets. At the time of treatment this individual also exhibited a blastic phase of the disease. (It is well known that in this stage the disease becomes refractory to any form of therapy.) The reason for failure in Case 13 is not clear. Since marked splenic enlargement existed, $\mathrm{P}^{32}$ therapy was stopped and X-ray given to the spleen with satisfactory results. In the remaining 13 cases, immediate and excellent response was obtained in the white blood cell count and associated with this, a rise in the red cell count was noted in most cases. As is shown in Table III, the maturation of the cells definitely changed, with a clear-cut decrease in the immature cells in practically every instance following treatment. (Arbitrarily we have considered those cells ranging from the early blastic stages to and including the myelocytic stage as immature.) It may also be seen that the average initial white blood cell count was 170,000 per cubic millimeter, ranging from 69,000 to 299 ,000 , and following treatment a composite of the maximum response showed a drop to 17,000 cells per cubic millimeter of blood. The initial red blood cell count was 3.1 million per cubic millimeter and at the end of three months the average red blood cell count rose to 4.1 million cells per cubic millimeter.

In our series of cases, the platelet counts were relatively unaffected during the first course of treatment. This observation agrees with those of Warren (7), who stated that the megakaryocytes showed little damage with moderate dosage. However, subsequent courses tend to depress the platelet count and the rate of decrease in the platelets serves as an important criterion for the continuation of treatment. Figure 7 shows graphically the initial response of the white and red cell count for each patient. It is noted that a uniform reduction of the white cell count occurs promptly as well as a clear-cut increase in the red cell count. Figure 8 is a composite curve of the initial response to $\mathrm{P}^{32}$.

A gradual reduction in the size of the spleen occurred in all 13 cases. In several the decrease was dramatic. Anorexia and weakness, the most common and distressing symptoms, disappeared at 


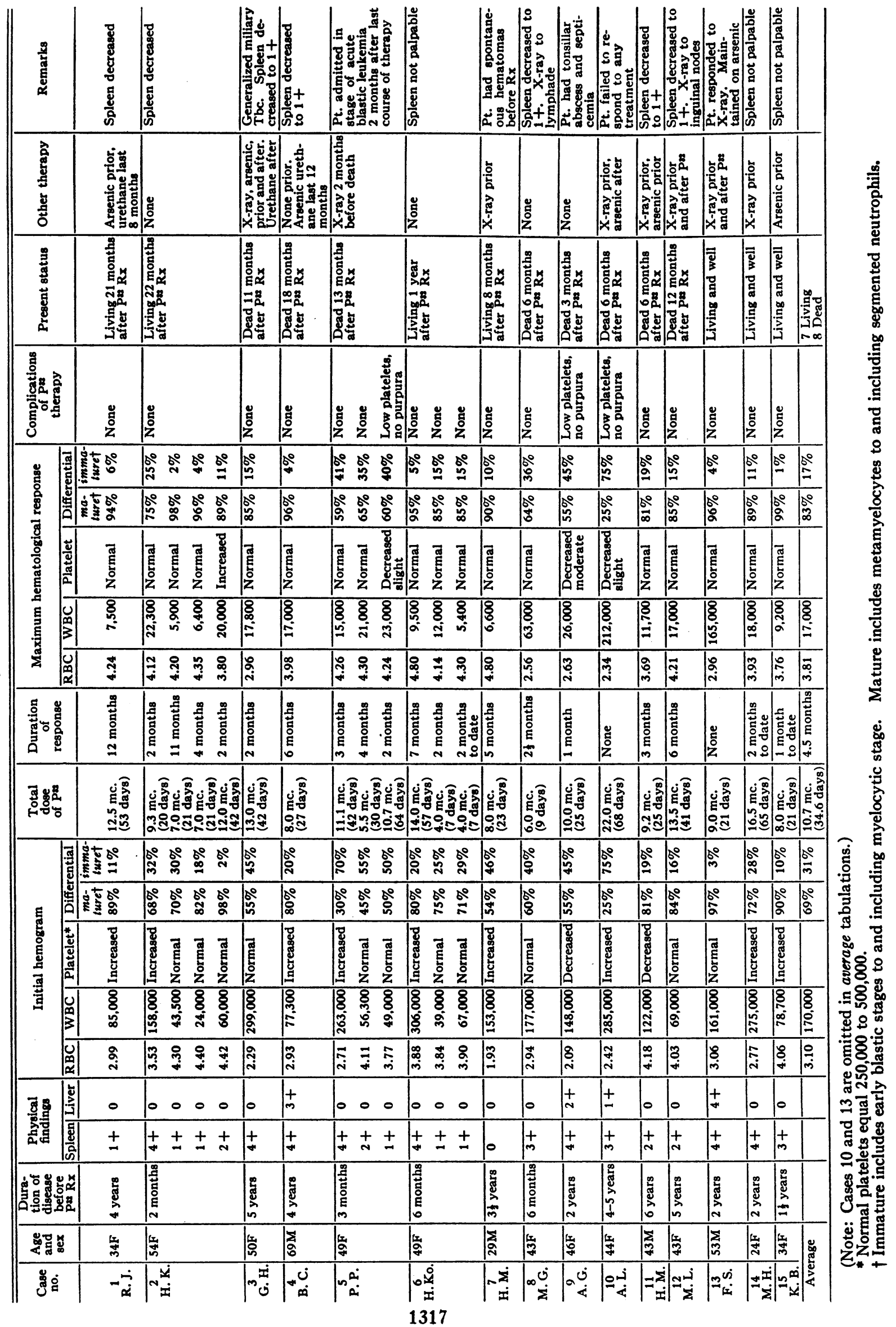


a comparatively early date. The duration of remissions ranged from two to 12 months with an average of about 4.5 months.

In studying the cases it appears that the treatment of chronic myeloid leukemias with $\mathrm{P}^{32}$ is highly satisfactory, but that treatment solely by this means for all relapses is of dubious wisdom and perhaps to be discouraged. In those cases with splenic enlargement which do not respond, or at best respond poorly to $\mathrm{P}^{32}$, it is often advisable to treat the spleen with $\mathrm{X}$-ray when a relapse occurs. It is our strong impression that the continued and persistent use of $\mathrm{P}^{32}$ for every relapse will lead to a hyperplastic bone marrow in a great percentage of cases. It is probably advisable to intersperse other forms of therapy, such as localized X-ray, or ar-

CHRONIC MYELOID LEUKEMIA
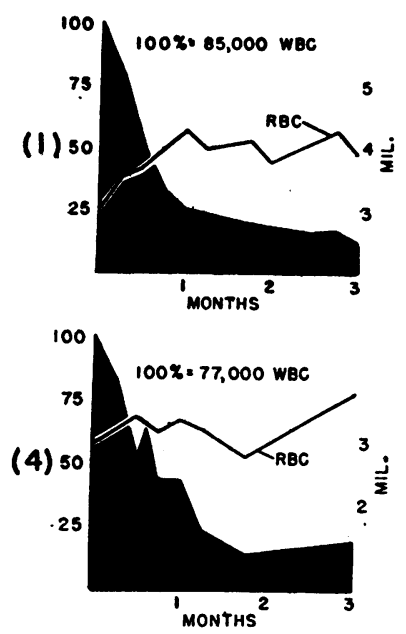

(2) 50

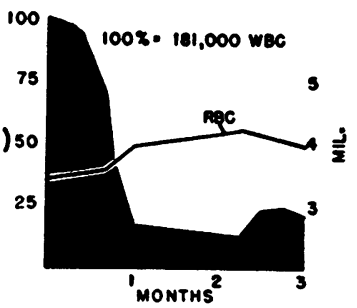

(5) 50
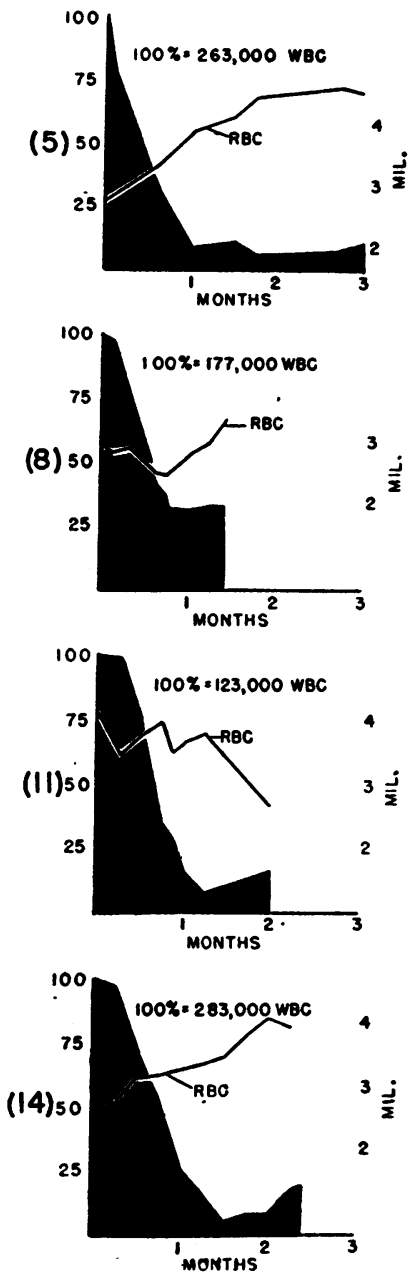

(3) 50

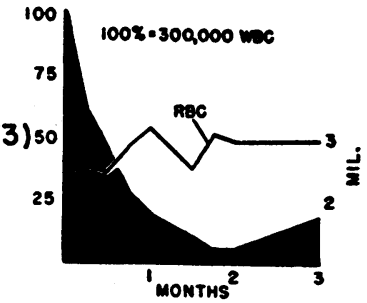

(6)
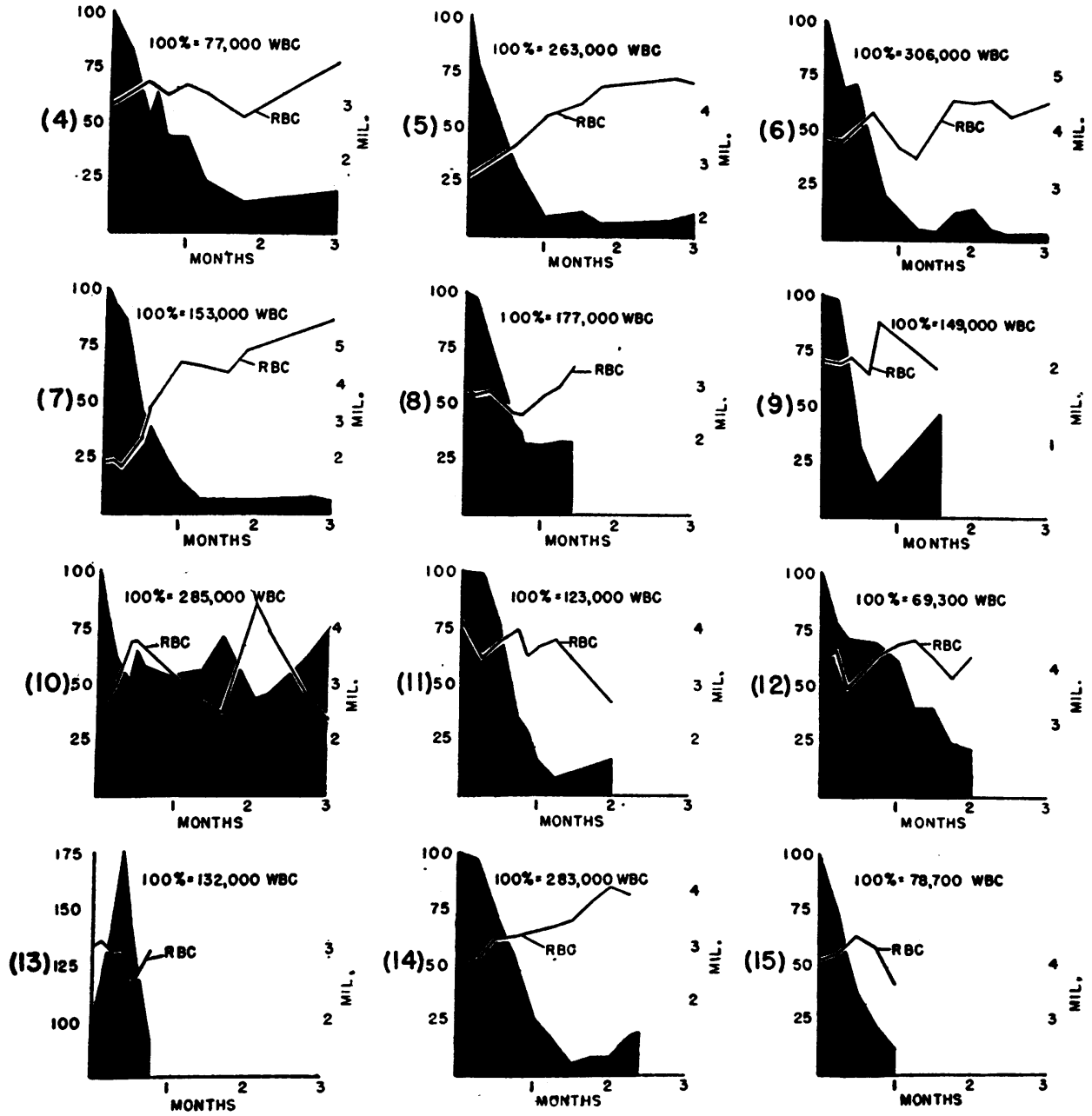

FIG. 7

These curves show the initial hematological response to $P^{82}$ in all 15 cases. 
CHRONIC MYELOID LEUKEMIA

COMPOSITE CURVE INOICATING

MMEOIATE HEMATOLOGICAL RESPONSE

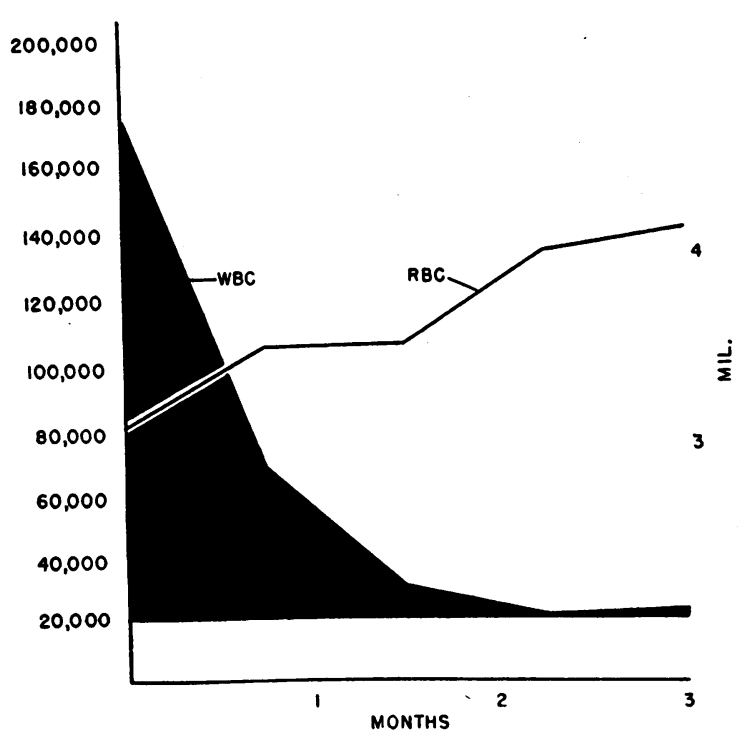

FIG. 8

Cases 10 and 13 were omitted from this curve. These cases show no response to treatment.

senic (if it proves effective), to increase the intervals between periods of $\mathrm{P}^{32}$ therapy.

The criteria for selecting patients have been based upon :

1. The level of the white cell count. No cases having counts of less than 20,000 white blood cells per cubic millimeter of blood were accepted for treatment.

2. The thrombocyte level. The number of thrombocytes is very important. The patients with low platelet counts were generally treated cautiously or not accepted for treatment. If the platelet count appeared to drop rapidly, treatment was often discontinued for a short interval. During the first course unusual thrombocyte depression does not appear to be a problem, but on retreatment for subsequent relapses the thrombocyte level must be carefully observed.

3. Character of the bone marrow. We have been insistent that the bone marrow show definite hyperplasia before treatment was given.

4. Maturation of the white cells. The degree of immaturity to the present has in no way affected our selection of cases for treatment, but if the number of immature cells are unusually high, one must always consider the approach of an acute blastic phase of the disease which is known to respond poorly.

Of the 15 cases treated with $\mathrm{P}^{32}$, seven are living. The average duration of life in those patients that have died is 3.5 years. This corresponds favorably with the duration of life in a recent report made by Lawrence (14).

Dosage. Again, no hard and fast rules have been applied. It has been found that doses of 1.5 to $2 \mathrm{mc}$. given at weekly intervals usually produce the desired response after administration of a total dose of 8 to $12 \mathrm{mc}$. When the white blood cell count approaches 20,000 per cubic millimeter, treatment has been discontinued. As noted by Lawrence (14), it is probably unwise to bring the white blood cell count to normal levels since an effort to depress the white cell count to a normal level requires additional phosphorus and the risk of thrombocytopenia, anemia and serious leukopenia is increased. In the 13 cases which showed satisfactory response, the average dose required to effect hematological remission was $10.7 \mathrm{mc}$. over a period of 34 days. If one should wish to use a single large dose, there is probably enough experience accumulated in the past ten years to permit treatment of these patients in this manner, but the distribution of $\mathrm{P}^{32}$ over a period of a month permits integration of the white blood cell response, and fractionation of the dosage is unquestionably the preferred method of treatment.

Chronic lymphatic leukemia. As has been stated before, the rationale for treating this form of leukemia with $\mathrm{P}^{32}$ is not clear-cut. In the majority of cases, although leukemic infiltration is present in bone, the disease is predominantly in lymphoid tissue. The marrow does not have the hyperplasia of all the cellular elements present in myeloid leukemia and in many cases actual damage of the erythroid and megakaryocytic cells is severe. Treatment with $\mathrm{P}^{32}$ in most cases serves to depress a bone marrow which appears to have already suffered damage from infiltrating lymphocytic elements. The six cases of chronic lymphatic leukemia selected for treatment, as stated previously, had become resistant to X-ray or were approaching a terminal state. It is doubtful that any form of therapy would have been efficacious. 
Table IV gives the clinical data of these six patients. All patients were dead within seven months after $\mathrm{P}^{\mathbf{3 2}}$ was started. These cases all had diffuse infiltration of mature and immature lymphocytes on bone marrow biopsies. In all but two cases the initial thrombocyte counts were reduced. (Generally, low initial thrombocyte counts are contraindications to treatment with $\mathrm{P}^{32}$, but in these cases it was felt that an attempt should be made to produce remission no matter how temporary.) Three of the patients were transfused during treatment. The white blood cell count per cubic millimeter of blood ranged initially from 111,00 to 719,000 with an average of 376,000. After treatment the white cell count averaged 78,000 per cubic millimeter, indicating a fair hematological response to $\mathrm{P}^{32}$. As was anticipated, in a number of the cases treatment was stopped because of purpura or extremely low. platelet count. It is doubtful whether $\mathrm{P}^{32}$ alone contributed to the purpura, since two cases had initial hemorrhagic tendencies prior to therapy.

Case 2 is of interest in one respect which deserves mention. A marked hemolytic phenomenon which was present initially showed dramatic cessation following therapy with a concomitant and unusual response in the white cell count which dropped from 216,000 to 8,000 in only 14 days, after a total of $6 \mathrm{mc}$. of $\mathrm{P}^{82}$.

Widespread metastases to bone arising from breast carcinoma. Fourteen cases of widespread carcinomatosis of bone from primary breast carcinoma have been treated with what may prove promising results. These cases are to be reported elsewhere and are, therefore, not included in detail in this report. The rationale for treating these cases is based on a well-established fact that malignant tumor cells have a greater $\mathrm{P}^{32}$ uptake than most normal cells and that selective uptake of phosphorus in bone is large compared with other tissues, thus producing long-continued selective irradiation of bone. The most striking feature is the relief of bone pain following the treatment. It is not possible at this time to have any definite opinion as to increase in longevity of these patients. In at least one case there was marked deposition of calcium in destructive lesions demonstated by $\mathrm{X}$-ray. In others the osteoclastic process appeared to be arrested. In all these cases the dosage of $\mathrm{P}^{32}$ was pushed to considerably higher levels at the risk of producing anemia, thrombocytopenia and severe leukopenia. From 18 to $20 \mathrm{mc}$. were administered in three to four weeks-two cases showing severe purpuric manifestations which subsequently improved. All cases had a moderate to marked depression of the white blood cell count which gradually returned to levels approaching normal after three months.

Treatment of this type with comparatively large doses begins to assume a heroic aspect, but the gravity of the process may justify such an approach if the therapy has promise of any beneficial effects.

\section{DISCUSSION}

There is ample evidence experimentally and by empirical clinical application in chronic leukemias and polycythemias that radiophosphorus is an important and effective means of treating these conditions. The cases of polycythemia and leukemia reported here corroborate the promising findings reported by others.

It appears that polycythemias respond unusually well to $\mathrm{P}^{32}$ but it is well to remember that this disease is a long-standing chronic process which can be controlled by venesection, although with some difficulty. The apparent superiority of $\mathrm{P}^{32}$ over other methods (X-rays, phenylhydrazine and venesection) must be weighed against the possible complications of $\mathrm{P}^{32}$ treatment. These are possible thrombocytopenia, leukopenia and anemia. It is still difficult to say what the eventual long time results may be with continued $\mathrm{P}^{32}$ application. It appears true that the duration of the remissions, the lowered incidence of the complications of the disease, and the hematological response are quite striking and superior to other means of therapy. It may well be true that $\mathrm{P}^{32}$ is the treatment of choice.

In the case of chronic myeloid leukemia the response is prompt, the remissions are of considerable duration and the complications, at least with moderate dosage, appear to be minimal. It is also clear, however, that it is not possible to eradicate the disease with radiophosphorus and an effort to destroy every vestige of leukemic infiltration would irreparably damage the hematopoietic system and perhaps other systems. It is therefore, unwise, as noted previously, to make any such attempt and the use of $\mathrm{P}^{32}$ should be limited 


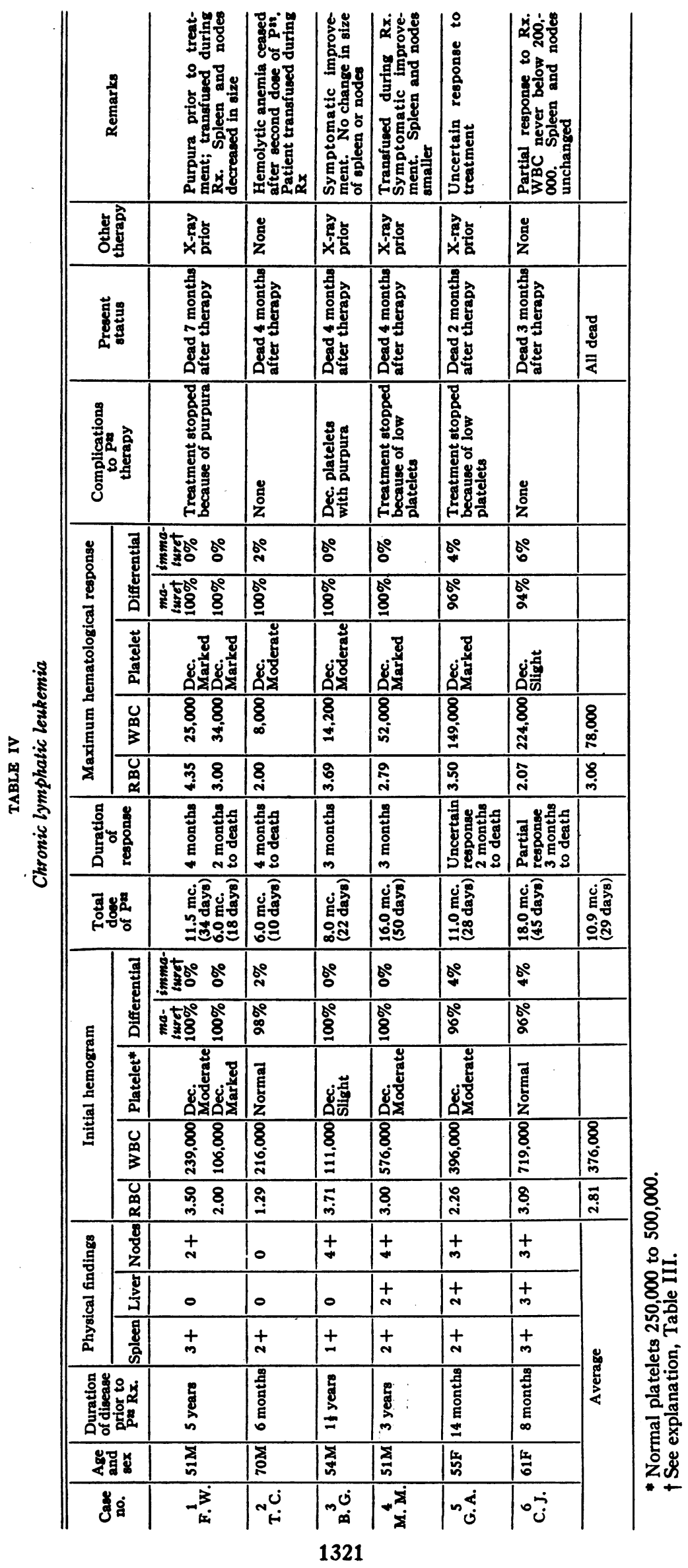


to inducing remissions with as little phosphorus as possible. The impression is strong that continued application of $\mathrm{P}^{32}$ for every relapse with amounts required to bring the leukocyte count to low levels would undoubtedly severely injure the bone marrow and would result in an aplastic marrow in many cases. The use of radioactive phosphorus has several advantages over X-ray in that :

1. Patients have no radiation sickness.

2. The administration of radiophosphorus is simple.

3. It may have the theoretical advantage over $\mathrm{X}$-ray in that phosphorus tends to seek out the most active cells and also selectively irradiates the bone marrow which in the case of chronic myeloid leukemias is, in most instances, the most important site of the disease.

$\mathrm{P}^{32}$ cannot be employed without a thorough knowledge of the effects of its radiation, the character of its distribution in tissue, the consequences of possible over-dosage, and clinical course of the patient. Although $\mathrm{P}^{\mathbf{3 2}}$ has been used for over ten years, it is not yet completely removed from the realm of experiment. A great many hiatuses exist in the information concerning the effect of $\mathrm{P}^{32}$.

In the case of chronic lymphatic leukemias, satisfactory results have been reported by others, and radiophosphorus is unquestionably useful in this disease. It is our opinion, however, in reviewing the appearance of the bone marrow and the general character of response of patients treated with $\mathrm{P}^{32}$, that lymphatic leukemias should be spared the intensive radiation of the bone marrow which occurs with $\mathrm{P}^{32}$. The appearance of the bone marrow in this disease generally indicates that hyperplasia is not present and that the erythroid and megakaryocytic elements may actually be damaged.

The application of $\mathrm{P}^{32}$ for widespread malignancies must be considered purely experimental. In general, treatment of these conditions with $\mathrm{P}^{32}$ has been poor.

The dosage of $\mathrm{P}^{82}$ is still not fully standardized. The amount of phosphorus administered is gauged primarily by the clinical response, by the size of the patient, by the extent of the disease and by careful observation of the known complications-leukopenia, anemia, thrombocytopenia. In general we have, as noted above, used a routine of approximately $2 \mathrm{mc}$. a week to a total of 10 to $12 \mathrm{mc}$. for the chronic myeloid leukemias and, on the average, a total of $10 \mathrm{mc}$. in a 12 day period in the case of polycythemias. This works out to be about 150 microcuries per kilogram in a ten to 14 day period and a comparable amount in a 30 day period for chronic myeloid leukemias. In the case of chronic leukemias, fractionation is the preferred method of treatment since it permits integration of the hematological response into the treatment. In the case of polycythemia, fractionation over the period of time required for maximum responses (three or four months) would be impractical and we have, therefore, chosen to administer the dose, as have others, over a short period.

\section{SUM MARY}

1. The rationale for using $\mathrm{P}^{32}$ as an internally distributed source of radiation and its selective uptake by various normal and tumor tissues has been reviewed. The basis for this, which rests on experimental, biological and clinical work, is discussed.

2. The pertinent information necessary to apply $\mathrm{P}^{32}$ effectively is noted. Experimental and clinical data in this regard are presented. The physical characteristics of $\mathrm{P}^{32}$ and its behaviour biologically are included.

3. Primary polycythemias and chronic myeloid leukemias are effectively treated with radioactive phosphorus. Ten cases of primary polycythemia and 15 of chronic myeloid leukemia are reported, confirming the observations of others. $\mathrm{P}^{\mathbf{3 2}}$ has also been used for a variety of malignant conditions other than leukemia. None of the responses have been striking. Mention is made of possible beneficial application to widespread metastases to bone from carcinoma of the breast.

\section{BIBLIOGRAPHY}

1. Lawrence, J. H., Scott, K. G., and Tuttle, L. W., Studies on leukemia with the aid of radioactive phosphorus. Internat. Clin., 1939, 3, 33.

2. Low-Beer, B. V. A., Lawrence, J. H., and Stone, R. S., The therapeutic use of artificially produced radioactive substances, radiophosphorus, radiostrontium, radioiodine, with special reference to leukemia and allied diseases. Radiology, 1942, 39, 573. 
3. Erf, L. A., Tuttle, L. W., and Lawrence, J. H., Clinical studies with the aid of radiophosphorus. IV. The retention in the blood, the excretion and the therapeutic effect of radiophosphorus on patients with leukemia. Ann. Int. Med., 1941, $15,487$.

4. Fitz-Hugh, T., and Hodes, P. J., Clinical experience with radio-phosphorus in the treatment of certain blood dyscrasias. Am. J. M. Sc., 1942, 5, 662.

5. Kenney, J. M., Radioactive phosphorus as a therapeutic agent in malignant neoplastic disease. Cancer Research, 1942, 2, 130.

6. Craver, L. F., Treatment of leukemias by radioactive phosphorus. Bull. New York Acad. Med., 1942, 18, 259.

7. Warren, S., The therapeutic use of radioactive phosphorus. Am. J. M. Sc., 1945, 209, 701.

8. Hall, B. E., Watkins, C. H., Hargraves, M. M., and Giffin, H. Z., Radioactive phosphorus in the treatment of polycythemia vera; results and hematologic complications. Am. J. M. Sc., 1945, 209, 712.

9. Erf, L. A., Primary polycythemias; remissions induced by therapy with radiophosphorus. Blood, 1946, 1, 202.

10. Erf, L. A., Radiophosphorus as the treatment of choice in primary polycythemia. Am. J. Med., $1946,1,362$.

11. Hoster, H. A., and Doan, C. A., Studies in Hodgkin's syndrome. IV. The therapeutic use of radioactive phosphorus. J. Lab. \& Clin. Med., 1945, 30, 678.

12. Reinhard, E. H., Moore, C. V., Bierbaum, O. S., and Moore, S., Radioactive phosphorus as a therapeutic agent. J. Lab. \& Clin. Med., 1946, 31, 107.

13. Doan, C. A., Wiseman, B. K., Wright, C., Geyer, J. H., Myers, W., and Myers, J. W., Radioactive phosphorus, $\mathrm{P}^{23}$; A six year clinical evaluation of internal radiation therapy. J. Lab. \& Cin. Med., 1947, 32, 943.

14. Lawrence, J. H., Dobson, R. L., Low-Beer, B. V. A., and Brown, B. R., Myelogenous leukemia, J. A. M. A., 1948, 136, 672.

15. Cohn, W. E., and Greenberg, D. M., Studies in mineral metabolism with the aid of artificial radioactive isotopes. I. Absorption, distribution, and excretion of phosphorus. J. Biol. Chem., 1938, 123, 185.
16. Bulliard, H., Grundland, I., and Moussa, A., Détection $\mathrm{du}$ phosphore des phosphatides surrenaliens par le radio-phosphore. Compt. rend. Acad. d. Sc., 1938, 207, 745.

17. Kenney, J. M., Marinelli, L. D., and Woodward, H. Q., Tracer studies with radioactive phosphorus in malignant neoplastic disease. Radiology, 1941, 37,683 .

18. Lawrence, J. H., and Scott, K. G., Comparative metabolism of phosphorus in normal and lymphomatous animals. Proc. Soc. Exper. Biol. \& Med., 1939, 40, 694.

19. Jones, H. B., Chaikoff, I. L., and Lawrence, J. H., Phosphorus metabolism of neoplastic tissues (mammary carcinoma, lymphoma, lymphosarcoma) as indicated by radioactive phosphorus. Am. J. Cancer, 1940, 40, 243.

20. Lawrence, J. H., Tuttle, L. W., Scott, K. G., and Connor, C. L., Studies on neoplasms with the aid of radioactive phosphorus. I. The total phosphorus metabolism of normal and leukemic mice. J. Clin. Invest., 1940, 19, 267.

21. Tuttle, L. W., Erf, L. A., and Lawrence, J. H., Studies on neoplasms with the aid of radioactive phosphorus. II. The phosphorus metabolism of the nucleoprotein, phospholipid, and acid soluble fractions of normal and leukemic mice. J. Clin. Invest., 1941, 20, 57.

22. Forssberg, A., and Jacobsson, F., Studies on BrownPearce rabbit carcinoma with aid of radioactive isotopes. Acta radiol., 1945, 26, 523.

23. Forssberg, A., A study of distribution of radioactive phosphorus in three cases of cancer. Acta radiol., 1946, 27, 88.

24. Marshak, A., Uptake of radioactive phosphorus by nuclei of liver and tumors. Science, 1940, 92, 460.

25. Erf, L. A., and Lawrence, J. H., Clinical studies with the aid of radioactive phosphorus. I. The absorption and distribution of radiophosphorus in the blood and its excretion by normal individuals and patients with leukemia. J. Clin. Invest., 1941, 20, 567.

26. Osgood, E. E., Aebersold, P. C., Erf, L. A., and Packham, E. A., Studies of effects of million volt roentgen rays, 200 kilovolt roentgen rays, radioactive phosphorus, and neutron rays by marrow culture technique. Am. J. M. Sc., 1942, 204, 372. 